\title{
Do companies in the pharmaceutical supply chain earn excess returns?
}

\author{
Neeraj Sood ${ }^{1} \cdot$ Karen Mulligan $^{1}$ (D) Kimberly Zhong ${ }^{2}$
}

Received: 24 October 2019 / Accepted: 21 November 2020 / Published online: 4 January 2021

(c) The Author(s), under exclusive licence to Springer Science+Business Media, LLC part of Springer Nature 2021

\begin{abstract}
Rising drug spending has led to increased calls to curtail drug costs. However, it is unclear where to target policy solutions. We estimated excess returns (the extent to which a firm's profits are higher than expected given the risk associated with their investments) for manufacturers and middlemen in the pharmaceutical supply chain to determine who is making excessive profits. Excess returns were calculated as the difference between return on invested capital and the expected returns given risk, which is known as the weighted average cost of capital. We compared excess returns for manufacturers and middlemen to the average for S\&P 500 companies. We find that both manufacturers and middlemen have higher excess returns in 2013-2018 compared with the S\&P 500. However, if we treat research and development $(\mathrm{R} \& \mathrm{D})$ as an investment rather than an expense, we find that excess returns for pharmaceutical manufacturers are lower than the S\&P $500(1.7 \%$ vs. $3.6 \%$ ), but biotech manufacturers $(9.6 \%)$, wholesalers $(8.1 \%)$, and insurers/PBM/retailers (5.9\%) continue to have significantly higher excess returns compared to the S\&P 500. Our findings suggest public policies that promote competition in all areas of the pharmaceutical supply chain are important avenues for curtailing drug spending.
\end{abstract}

Keywords Pharmaceutical supply chain $\cdot$ Excess returns $\cdot$ Drug prices $\cdot$ Drug price policy

JEL Classification I1 $1 \cdot \mathrm{I} 18 \cdot \mathrm{G} 30$

Electronic supplementary material The online version of this article (https://doi.org/10.1007/s 1075 4-020-09291-1) contains supplementary material, which is available to authorized users.

Neeraj Sood

nsood@healthpolicy.usc.edu

1 Sol Price School of Public Policy and Leonard D. Schaeffer Center for Health Policy and Economics, University of Southern California, 635 Downey Way, Verna and Peter Dauterive Hall (VPD), Los Angeles, CA 90089, USA

2 University of Southern California, Los Angeles, CA, USA 


\section{Introduction}

In recent years, high and rising drug spending and prices have received scrutiny from the media (Kliff 2018; Thomas and Ornstein 2018; Hancock and Tribble 2018; Drash 2018). This has led to increased interest by policymakers in curtailing drug spending. However, it is unclear where to target policy solutions. Some contend that pharmaceutical companies are primarily responsible for high drug spending (Pharmaceutical Care Managment Association 2018). A recent GAO report shows that more than two-thirds of all drug companies saw an increase in profit margins between 2006 and 2015 and the profit margins of the top 25 largest drug companies well exceed those of companies in other industries (United States Government Accountability Office 2017). Others contend that high returns on pharmaceutical investment are justified by the risks associated with the development of new therapies. For example, only $7-10 \%$ of all drugs that have undergone Phase 1 clinical trials are eventually approved by the FDA, although the risk of failure is lower for Phase III clinical trials (Wong et al. 2018; Hay et al. 2014; Thomas et al. 2016), which allows companies to adjust their research and development (R\&D) spending to account for relative risk at various phases in the drug development process.

Despite the high risk associated with developing new therapies, estimates from 1978 to 1987 found returns in the pharmaceutical industry exceeded other industries by 2-3 percentage points, even after accounting for risk associated with investment (US Congress, Office of Technology Assessment 1993). This finding indicates pharmaceutical companies earned "excess returns"- a measure commonly used in the finance literature to estimate the extent to which firms generate higher than expected returns given the risk associated with their investments (Damodaran 2012; Berk and DeMarzo 2017; Palepu and Healy 2013). Berndt et al. (2015) found positive lifetime profitability (net of R\&D costs) for drugs introduced in the 1990s, but that profitability has since declined, and became negative for the 2005-2009 drug cohort (Berndt et al. 2015). Although more recent studies of excess returns have not been conducted, Ledley et al. (2020) found that for 2000-2018, companies in the pharmaceutical industry were more profitable compared with companies in the Standard and Poor's 500 Index (S\&P 500), which aligns with GAO results (United States Government Accountability Office 2017; Ledley et al. 2020). While the findings from both studies support the argument that companies in the pharmaceutical sector are generally profitable, they cannot be interpreted as profitability being "too high" since high returns might just be a reflection of higher risk.

Despite potentially high profits in the pharmaceutical industry, focusing on pharmaceutical companies as the sole drivers of high drug prices is potentially misleading given the complexity of the pharmaceutical supply chain in the US. Ultimately, drug spending is determined through negotiations between multiple stakeholders, including pharmaceutical companies, insurers, pharmacy benefit managers (PBMs), pharmacies, and wholesalers, with each stakeholder obtaining a share of profits from drug sales. A recent study used data from firm financial statements in the pharmaceutical supply chain and showed that for a hypothetical $\$ 100$ spent on prescription drugs by a consumer, manufacturers kept $\$ 58$ ( $\$ 15$ of which is net profit) and insurers, PBMs, pharmacies, and wholesalers ("middlemen") collectively kept $\$ 42$ (\$8 of which is net profit) (Sood et al. 2017). While this analysis confirms manufacturers capture the most profits compared with other companies in the pharmaceutical supply chain, the study does not determine whether profits are "excessive."

Our study extends and complements the existing literature by estimating excess returns to explore whether any sector of the pharmaceutical supply chain-manufacturers, 
wholesalers, or insurers/PBMs—is earning excessive profits between 2013 and 2018. A firm makes "excess returns" if it generates more profits than expected given the risk associated with their investments. Excess returns account for the riskiness of investments as firms that make higher profits by making riskier investments will also face a higher cost of capital in equity (stocks) or debt (bonds) markets to raise funds that finance investments. We compare the excess returns in each sector of the pharmaceutical supply chain to excess returns of firms in the S\&P 500 — an industry benchmark consisting of large publicly traded companies that represent about $80 \%$ of the US equity market by market value.

Our study is conducted at the firm-level and aggregated by industry for a cross-industry comparison. One critique of industry-level studies is that they fail to capture firm heterogeneity with respect to $\mathrm{R} \& \mathrm{D}$ depreciation rates, product diversification, and product life cycles, and therefore are subject to measurement error (DiMasi and Grabowski 2012). To address this criticism, a related literature estimates the returns to pharmaceutical R\&D using a life-cycle approach to calculate costs and returns for individual drugs (Berndt et al. 2015; DiMasi 2002; Grabowski and Vernon 1994; Grabowski et al. 2002). While this approach incorporates within and across company heterogeneity into R\&D returns calculations, it also has limitations. First, the approach relies on proprietary firm data on clinical trials, the costs of conducting the clinical trials and the success rates of clinical trials. Second, R\&D costs are typically not observed at the level of individual drugs and thus studies rely on industry averages. Similarly, individual drug revenue data are not always observed for the full life cycle, and therefore calculations rely on projections (Berndt et al. 2015). Finally, while the life-cycle approach is more widely used in pharmaceutical R\&D studies, our aim is to compare returns for companies within the pharmaceutical supply chain to returns of other companies in the S\&P 500 rather than determining the value of R\&D for specific drugs. Therefore, our analysis is conducted using an industry-level approach.

We estimate two measures of excess returns: one uses a traditional accounting approach and treats R\&D expenditures as an expense; the other estimates "adjusted excess returns," treating R\&D expenditures as investment. The second approach explicitly recognizes that $R \& D$ expenditures yield new products that increase profits in future years, and are therefore more similar to investments than traditional expenses such as rent or salaries.

\section{Methods}

\section{Conceptual framework}

A firm makes "excess returns" if it generates higher than expected profits given the risk associated with their investments. Excess returns were therefore calculated as the difference between return on invested capital (ROIC) and the expected returns given risk, which is known as the weighted average cost of capital (WACC). ROIC is calculated as the ratio of current post-tax earnings to invested capital (i.e., assets) in the previous year. We considered two methods of calculating ROIC which differ in their treatment of R\&D spending. Unadjusted ROIC assumes R\&D spending is an expense in the period in which it occurs, and does not contribute to the value of the firm's assets. The assumption that R\&D spending is not an asset is counterintuitive, particularly for manufacturers, since R\&D expenditures on drug discovery eventually yield new commercial products that provide future returns for the firm. Thus, we also calculated adjusted ROIC, which treats R\&D expenses 
as investments (i.e., R\&D is capitalized), effectively recognizing R\&D expenditures' contribution to firm value (Damodaran 1999).

Companies finance assets with capital from either the debt or equity markets. In each of these markets investors expect a certain return on their investments, and the expected rate of return is the cost of capital. Investors' expected return in each market reflects the riskiness of investments, with higher risk investments expected to provide higher returns. WACC calculates each firm's average cost of capital by weighting the expected rates of return in the debt and equity markets by the fraction of firm capital financed by debt and equity. Industries with higher WACC are considered riskier.

Some companies may acquire new assets (e.g., drugs for pharmaceutical companies in particular) through mergers and licensing. For example, Gilead Sciences' acquisition of Pharmasset in 2011 provided the basis for their commercially successful Hepatitis C treatments. While these acquisitions will not appear as R\&D in the company's financial statements, they will be accounted for in other aspects of the financial statement, namely investments and earnings, and will therefore be captured in our excess returns calculation. Similarly, drug (or other types of R\&D) failures, while not directly observable, will be implicitly accounted for in excess returns. Specifically, failed R\&D (drugs in particular for pharmaceuticals) will incur an up-front cost, which will impact R\&D expenses, but will not provide future returns to the company, which will be reflected in lower earnings.

\section{Data and sample}

We collected firm-level financial data for 2013 to 2018 from financial statements of publicly traded companies compiled by CompuStat Fundamentals Annual (Standard \& Poor's/ Compustat 2013). Our main sample included all companies in the S\&P 500 from 20132018. Since the composition of the S\&P 500 changes each year, the underlying companies in our index change over time. Companies in the pharmaceutical supply chain were identified using Standard Industrial Classification (SIC) codes: manufacturers included pharmaceuticals $(\mathrm{SIC}=2834)$ and biotech $(\mathrm{SIC}=2836)$ and middlemen included insurers (SIC =6834), wholesalers (SIC =5122), and retailers/pharmacies/PBMs (SIC=5912). Our final manufacturer sample included 28 companies with aggregate average revenues equal to $\$ 410$ billion per year, and average aggregate $R \& D$ spending of $\$ 72.1$ billion per year. Our final middlemen sample included 11 companies with aggregate average revenues equal to $\$ 1205$ billion per year and $\$ 0.3$ billion in $\mathrm{R} \& \mathrm{D}$ spending per year. The remaining companies in the S\&P 500 that are not in the pharmaceutical supply chain were used to create an overall benchmark for comparison.

Although the S\&P 500 includes some of the largest publicly traded companies, some large publicly traded companies do not qualify for inclusion in the S\&P 500 based on criteria unrelated to size. For example, Novartis and Sanofi both have higher average revenues than most manufacturers in our main sample, but since they are headquartered outside the US, they do not qualify for inclusion in the S\&P 500. Therefore, we also analyzed an augmented sample that included other publicly traded companies in the pharmaceutical supply chain that are not part of the S\&P 500 but are relatively large. Specifically, we included companies from Sood et al. (2017) that were available in CompuStat. Our augmented sample added 6 manufacturers to the main sample, which accounted for an additional $\$ 230$ billion in aggregate average revenues and $\$ 39.3$ billion in aggregate R\&D spending per year. Three additional middlemen were in the 
augmented sample, accounting for $\$ 60$ billion additional aggregate average revenues per year Table 1 provides a full list of companies in the pharmaceutical supply chain for both samples.

We excluded companies in the pharmaceutical supply chain that were not in the S\&P 500 or identified as part of the augmented sample. These companies are generally smaller and are less comparable to the S\&P 500 companies that were used as a benchmark. The manufacturers in our main and augmented sample account for $85 \%$ of revenues for CompuStat companies within the relevant SIC codes (2834 and 2836). Similarly, the middlemen in our main and augmented sample account for $95 \%$ of revenues among CompuStat companies within the relevant SIC codes $(5122,5912$, and 6834).

\section{Excess returns calculations}

Excess returns are the difference between return on investment capital (ROIC) and the weighted average cost of capital (WACC). More specifically, we calculated estimated returns as follows:

$$
\text { Unadjusted Excess Returns }=\frac{\text { BBIT }_{t}-(\text { Income taxes })_{t}}{(\text { Investment capital })_{t-1}}-\text { WACC }_{t}
$$

where $t$ indexes the time period, EBIT is earnings before interest and taxes (i.e., operating income), and WACC is the weighted average cost of capital. R\&D spending is included as an expense (part of EBIT) in the unadjusted excess returns calculation. Adjusted excess returns capitalizes $R \& D$ so that it is treated as part of investment capital rather than an expense. Specifically, we have:

$$
\text { Adjusted Excess Returns }=\frac{\left(\text { EBIT }_{t}+\right.\text { RD Expense }}{t}-{\text { amortized } \left.R D_{t}\right)-(\text { Income taxes })_{t}}_{(\text {Investment capital })_{t-1}+(\text { Value of } R D \text { Asset })}-\text { WACC }_{t}
$$

The first adjustment (adding $R \& D$ expenses to the numerator) involves removing $R \& D$ expenses from operating income. Since $R \& D$ creates an asset, we then calculate the cumulative value of the asset. Assets (including R\&D) lose value over time, which requires an assumption for the useful life of an asset, or the time until the asset fully depreciates and loses all value. Previous studies estimated the life of $R \& D$ projects for pharmaceuticals was equal to 9.8 and 11.8 years (Hansen 1979; DiMasi et al. 1991). Therefore, we assume a useful life equal to 10 years for our study, and conduct sensitivity analyses that vary useful life to 8 years and 12 years. The asset is amortized uniformly (10\%) each year over its useful life to account for depreciation, and the amortized value is subtracted from earnings each year as an adjustment. The value of the asset in year $t$ is then equal to the sum of the unamortized $R \& D$ expenditures from the previous 10 years, which is represented mathematically by:

$$
\text { Value of } R D \text { Asset }{ }_{t}=\sum_{t=-(n-1)}^{t=0}(R D \text { expenditures })_{t} \frac{(n+t)}{n}
$$

where $t$ indexes the year (and the current year is normalized to 0 ), and $n$ is the useful life of the asset, which is equal to 10 in our case. Additional details of the excess returns calculations are provided in the Appendix in ESM. 


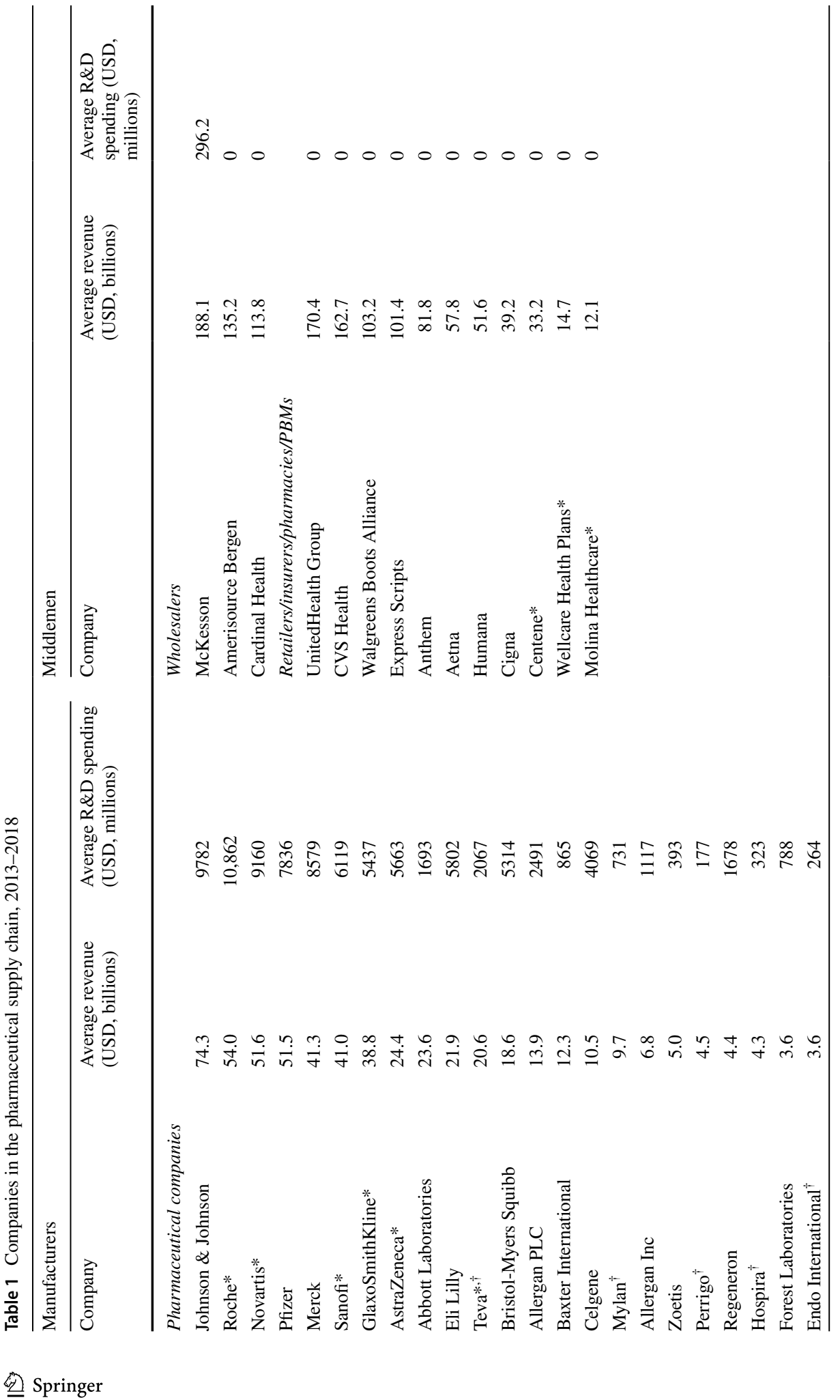




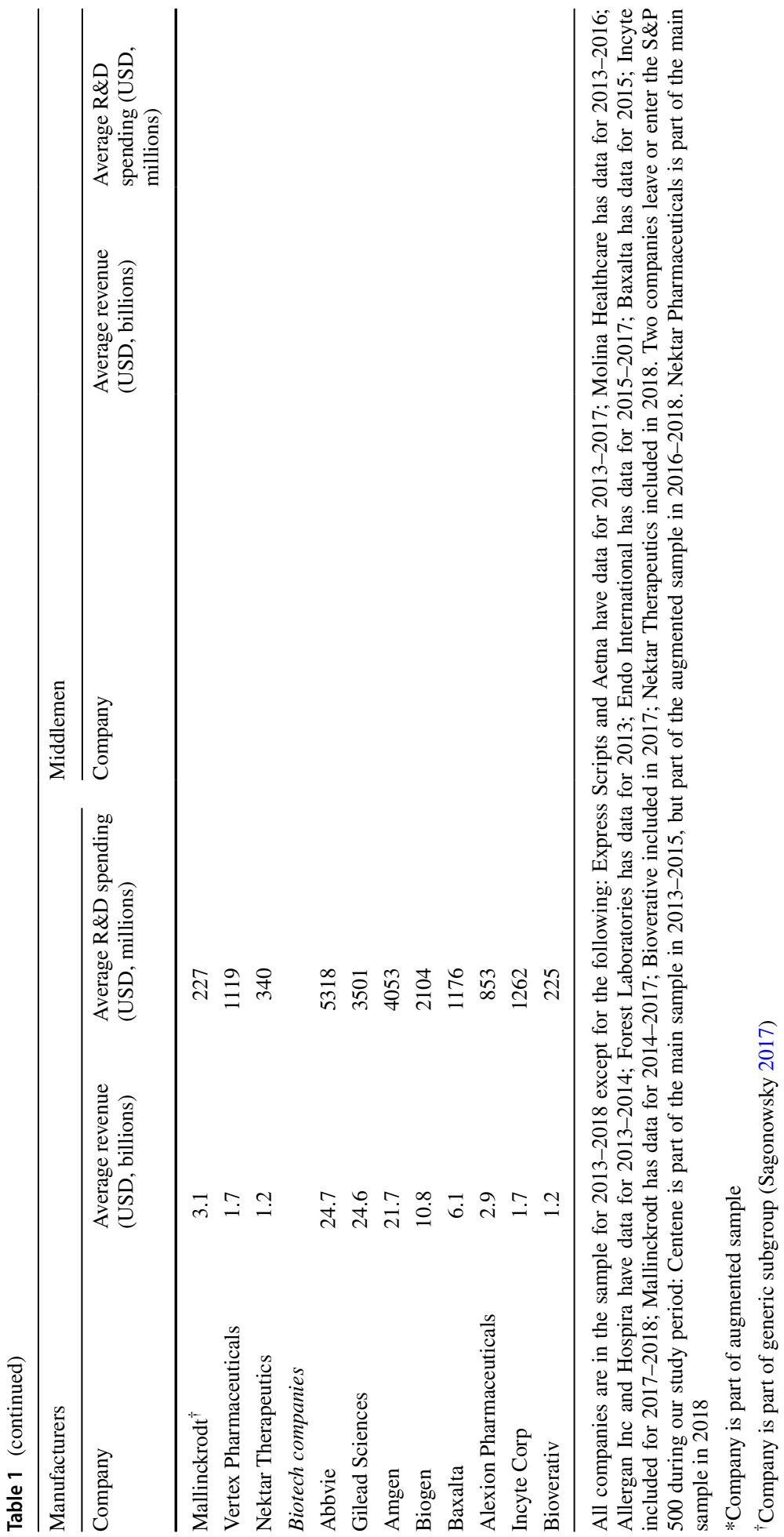




\section{Analysis}

We calculated average unadjusted and adjusted excess returns for both manufacturers and middlemen during 2013-2018 (pooled and annually) and compared these values to average excess returns for all other companies in the S\&P 500 during the same timeframe. Group averages were constructed by weighting individual firm returns by their previous year's investment capital. Since manufacturers and middlemen include a diverse group of firms, we focus on subgroups within those categories. Specifically, we split manufacturers into pharmaceutical and biotech companies and middlemen into wholesalers and other (insurers/retailers/pharmacies/PBMs). Although some manufacturers develop both pharmaceutical and biotech products, their financial data is not reported separately by product type. We therefore used the SIC code, which is based on a company's primary source of revenue, to classify which companies belong to each manufacturer subgroup. Ideally, we would like to analyze each sector of middlemen separately, but we could not disaggregate PBMs from insurers/retailers/pharmacies since many of the companies in our sample are involved in both parts of the supply chain. For example, the largest insurer in the US also owns one of the top 3 PBMs. Additionally, we conducted an analysis that splits manufacturers into groups based on whether their primary focus is on branded, generic, or other products since we expect them to have different levels of excess returns.

We conducted several sensitivity analyses using different excess return measures, including (1) weighting averages by revenues; (2) using unweighted average excess returns; (3) using median excess returns; and 4) calculating excess returns varying the useful life of R\&D assets.

\section{Limitations}

This work should be viewed in light of its limitations. First, we relied on data from firm financial statements, which can be misreported or manipulated through standard accounting methods. For example, companies may report artificially low R\&D to reduce expenses; this is one potential explanation for why most middlemen in our sample have zero average R\&D (Sherman and Young 2001). However, despite the potential for manipulation, we must take the data at face value. Second, we focused on the 6 most recent years of returns since industries for the WACC data were consistently defined over that timeframe. Although generating a crosswalk that maps industries from 2013 to 2018 to earlier years would allow us to look at a longer range of returns, it would introduce significant measurement error. Third, we were unable to disaggregate excess returns of PBMs from insurers and pharmacies/retailers since many companies in our sample were involved in multiple sectors of the supply chain and do not publish separate financial data for different sectors within the same company. Similarly, excess returns of pharmaceutical firms capture both the returns on all investments made by these firms. Although majority of investments by these firms are in the pharmaceutical sector some firms invest in other sectors such as consumer products and animal health. Finally, it is possible that reporting of rebates may lag sales and therefore cause revenues to be overstated (for manufacturers) or understated (for insurers/PBMs/retailers) in a given period, but our results pooled across years should help minimize this issue. 


\section{Results}

Unadjusted and adjusted excess returns are presented in Fig. 1 for subgroups of manufacturers, middlemen, and the S\&P 500. Pharmaceutical and biotech companies' unadjusted excess returns exceed their adjusted excess returns by 3.0 percentage point and 3.5 percentage points, respectively, reflecting their positive R\&D expenditures. In contrast, adjusted and unadjusted excess returns are roughly the same for middlemen, reflecting their low R\&D spending.

The results show that biotech companies earn significantly higher excess returns than other companies in the pharmaceutical supply chain and the S\&P 500, even after capitalizing R\&D. Pharmaceutical companies have unadjusted excess returns of $4.7 \%$ compared to $4.2 \%$ for the S\&P $500(p=0.63)$, but their adjusted excess returns are significantly lower compared with the S\&P $500(1.7 \%$ vs. $3.6 \%, p<0.01)$. In contrast, biotech companies have unadjusted excess return of $13.1 \%-8.9$ percentage points higher than the S\&P $500(p<0.01)$, and adjusted excess returns of $9.6 \%-6.0$ percentage points higher than the S\&P $500(p<0.01)$. Among middlemen, wholesalers have the highest adjusted excess returns, $8.1 \%$, compared to $5.9 \%$ for insurers/retailers/pharmacies/PBMs. Adjusted excess returns for both middlemen subgroups are significantly higher compared with the S\&P 500 $(p<0.01)$.

Our results are similar for the augmented sample, and were robust to (a) using medians rather than means when estimating excess returns; (b) using revenue rather than invested capital as weights for calculating average excess returns; and (c) using 8 or 12 years rather than 10 years as the expected life of R\&D assets. Results for the augmented sample and sensitivity analyses are presented in the Appendix in ESM.

We also examined whether annual adjusted excess returns between 2013 and 2018 for manufacturers and middlemen followed similar trends relative to the S\&P 500, and checked which companies contributed most to excess returns in a given sector by excluding each company from the analysis (see Appendix in ESM for full results). Table 2 presents adjusted excess returns by year for each sector in the pharmaceutical supply chain and the S\&P 500. For the remainder of the paper, we will refer to adjusted excess returns simply as excess returns.

Pharmaceutical companies had the consistently lowest excess returns across all years, and their returns declined in 2017-2018. Their excess returns ranged from 3.2 percentage points lower (in 2018) to 1.5 percentage points lower (in 2016) than the S\&P 500, and the difference in annual returns were insignificant for all years. Pharmaceutical excess returns were fairly robust to the exclusion of any one company (ranging from 1.0 to $2.1 \%$ pooled across all years), but were most sensitive to the inclusion of Johnson \&

Fig. 1 Average excess returns, 2013-2018

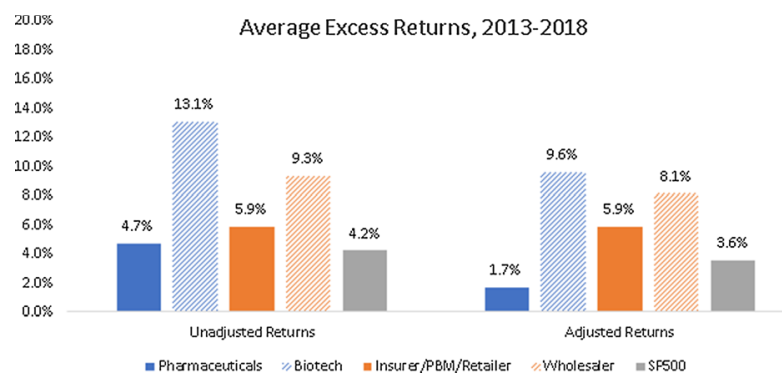


Table 2 Adjusted excess returns by year

\begin{tabular}{llllrrrr}
\hline & $\begin{array}{l}2013-2018 \\
\text { pooled (\%) }\end{array}$ & $2013(\%)$ & $2014(\%)$ & $2015(\%)$ & $2016(\%)$ & $2017(\%)$ & $2018(\%)$ \\
\hline Pharmaceuticals & 1.7 & 2.1 & 1.8 & 1.7 & 2.5 & 1.2 & 0.9 \\
Biotech & 9.6 & 8.5 & 15.2 & 17.2 & 10.2 & 2.2 & 8.7 \\
Wholesaler & 8.1 & 8.3 & 6.2 & 7.8 & 8.3 & 9.1 & 8.9 \\
Insurer/PBM/Retailer & 5.9 & 4.6 & 4.2 & 4.9 & 5.5 & $8.0 *$ & $7.2 *$ \\
S\&P 500 & 3.6 & 4.1 & 3.9 & 2.1 & 3.0 & 4.4 & 4.0 \\
\hline
\end{tabular}

Excess returns are weighted by investment capital. Companies in the main sample are listed in Table 1 $* p<0.05$ for test of difference from S\&P 500 excess returns

Johnson and Celgene (which had above average excess returns) and Abbott, Allergan PLC, and Merck (which had below average excess returns).

In contrast, biotech companies had consistently higher excess returns compared with the S\&P 500, but were also more volatile, ranging from - 1.9 percentage points lower than the S\&P 500 in 2017 to 13.1 percentage points higher than the S\&P 500 in 2015. Of note, biotech excess returns spiked in 2014-2015, then began to decline, and returned to their 2013 level by the end of the study period. This spike in excess returns can likely be explained by the approval of several blockbuster drugs in this sector: Gilead's first Hepatitis C drug was approved in 2013, and in 2014 both Gilead and Abbvie had Hepatitis $\mathrm{C}$ drug approvals. Biotech excess returns were most sensitive to the inclusion of Gilead and Abbvie (above average excess returns) and Amgen, which had below average excess returns.

Within the pharmaceutical and biotech sectors, three companies (Abbott, Baxter, and Zoetis) manufacture slightly different products (nutritional supplements, surgical devices, and animal pharmaceuticals) compared with the other branded manufacturers, and six companies primarily focus on generic drugs. Abbott, Baxter, and Zoetis earn lower average excess returns than the rest of the pharmaceutical industry $(-1.7 \%$ vs. 3.8\%). Branded manufacturers have higher unadjusted excess returns than the full manufacturer industry (7.1\% vs. 6.9\%; excluding Abbott, Baxter, and Zoetis). Similarly, their excess returns after capitalizing $R \& D$ are higher than the full manufacturer industry $(3.9 \%$ vs. $3.8 \%)$ as well as the S\&P 500.

Wholesalers had consistently higher annual excess returns compared with the S\&P 500 (ranging from 2.1 percentage points higher in 2014 to 5.1 percentage points higher in 2017). Only three companies belong to the wholesaler group, and all of them had excess returns that were greater than those for the S\&P 500 during the study period. In contrast with the pharmaceutical sector's excess returns, which declined over our study period, the insurer/PBM/retailer sector experienced an upward trend in excess returns. Specifically, excess returns for the insurer/PBM/retailer were less than 1 percentage point higher than the S\&P 500 between 2013 and 2015, and the difference increased to approximately 3 percentage points higher in 2017 and 2018.

Although most of the companies in the insurer/PBM/retailer group serve multiple functions, we further split the category into companies that are primarily PBM/retailer (Express Scripts, CVS, and Walgreens), and grouped the remaining companies as insurers. The insurers had slightly higher excess returns compared with the PBM/retailer group-6.2\% versus 5.4\% - and both experienced similar upward trends in excess 
returns during our study period. The insurer/PBM/retailer group's excess returns were relatively robust to the inclusion of any one company, ranging from 5.3 to $6.4 \%$. Excess returns were most sensitive to the inclusion of Cigna and United Health, both of which had above average excess returns, as well as Anthem, which had below average excess returns.

\section{Discussion}

We compared excess returns, which are calculated as return on investment net of the cost of capital for investment, for manufacturers and middlemen in the pharmaceutical supply chain and compared their returns with companies in the S\&P 500. We found that both manufacturers and middlemen have higher unadjusted excess returns in 2013-2018 compared with the S\&P 500. However, if we treat $R \& D$ as an investment rather than an expense, manufacturer returns are similar to those of S\&P 500 companies. Within sectors, biotech firms have higher returns than pharmaceuticals, and wholesalers have higher returns than insurance/PBMs/retailers during this period, irrespective of whether R\&D is treated as an investment or expense.

We are aware of one earlier study that estimated excess returns using the same methodology in our paper for the pharmaceutical industry, but it used data from 1978 to 1987 and did not include middlemen (US Congress, Office of Technology Assessment 1993). That study found adjusted returns in the pharmaceutical sector were 2-3 percentage points higher compared with other industries between 1978 and 1987. Our finding that excess returns for pharmaceutical companies are higher than the S\&P 500 if we treat R\&D as an expense is consistent with that study, but we show that adjusted excess returns for pharmaceutical companies are on par with the S\&P 500 for the most recent 5 years. Our findings for the pharmaceutical sector are also broadly consistent with more recent research that relied on analysis conducted at the drug level (Berndt et al. 2015; Deloitte 2019). While the results for Berndt et al. (2015) only span through drugs approved between 2005 and 2009, they found net economic returns were negative for the most recent drug cohort. Our range of excess returns for the pharmaceutical sector (2.1\% in 2013 to $0.9 \%$ in 2018 ) suggests the Berndt et al. (2015) result was not an outlier, and the trend of relatively low profitability net of $R \& D$ in the pharmaceutical sector has continued. This downward trend in returns to pharmaceutical R\&D corroborates Deloitte (2019): the rate of return to R\&D in 12 large cap companies declined from approximately 5\% in 2013 to 2\% in 2019 (Deloitte 2019).

Although Sood et al. (2017) describe returns for all sectors of the pharmaceutical supply chain, they do not compute excess returns. Examining excess returns (as opposed to returns) is important since the different sectors in the pharmaceutical supply chain have variable risk characteristics, and excess returns account for those differences. Our finding of positive excess returns is expected since our sample consists of profitable firms that are well-established in their lifecycle (Damodaran 2012). In contrast, companies in earlier lifecycle stages would likely have lower (and in some cases negative) excess returns since they are likely to have major investment outlays that have not yet realized into profits (Damodaran 2012). Although we expected positive excess returns for our sample, excess returns above an industry benchmark, such as the S\&P 500, might indicate barriers to entry, market inefficiency or other market failures that allow persistent excess returns.

Our results suggest the degree of competition in the pharmaceutical supply chain deserves greater scrutiny. The pharmaceutical supply chain is already highly consolidated 
with a few firms controlling several key sectors. For example, the top 3 PBMs account for $72 \%$ of the market (Fein 2018). In addition, the two most recent consolidation efforts involving CVS and Aetna (finalized in 2019) as well as Cigna and Express Scripts, will result in all three major PBMs being paired with large insurers. This vertical consolidation of the supply chain could create additional barriers to entry in the insurance and PBM markets and further limit competition. In light of these concerns, the American Medical Association has opposed the proposed mergers and lawmakers have asked the Federal Trade Commission to review whether past consolidation of the PBM market has benefited consumers (Tracer and Langreth 2018).

Among middlemen, wholesalers have the largest excess returns, and these are significantly higher than S\&P 500 excess returns even if we treat R\&D as an investment. This finding is consistent with a highly consolidated market- the three wholesale companies in our sample have controlled over $80 \%$ of the market since 1998, and have accounted for at least 90\% of revenues since 2007 (Britt 2007; FTC v. Cardinal Health, Inc., and Bergen Brunswig Corp. 1998). Reflecting a lack of competition, all three major wholesalers have been targeted by litigation for questionable practices such as illegal handling of oncology drugs and anticompetitive behavior, specifically the monopolization of local markets resulting in inflated prices (Pierson 2017; Federal Trade Commission 2015; Bernstein 2018). Weak competition could be the result of significant barriers to entry in this sector, since wholesaler regulations vary by state, and it is a substantial undertaking to establish and staff warehouses and distribution networks across the US, as well as implement and manage product tracking and verification systems to comply with the Drug Quality and Security Act (2013) and Guidelines for State Licensing of Wholesale Prescription Drug Distributors (1990). Moreover, since manufacturers prefer to work directly with the big three wholesalers, smaller wholesalers must frequently obtain product from the major wholesalers (Britt 2007).

In contrast with middlemen, monopoly power in the pharmaceutical and biotech sectors-derived through the US patent system-provides incentive for innovation that might not happen otherwise. Such monopoly power does lead to higher prices following drug approval, which would be harmful to patients if it results in underutilization of drugs. However, in markets with insurance, where a majority of patients face limited copays or other out of pocket costs, underutilization is arguably a minor issue (Lakdawalla and Sood 2013): roughly $8 \%$ of adults report they do not take drugs as prescribed to save money (Cohen and Villarroel 2013). Furthermore, patients in the US may tend to have access to drugs that are not available in markets outside the US (Danzon and Furukawa 2008; Haninger 2018). It is possible, however, that we provide too many incentives for certain types of R\&D, as argued by critics of "me too" or follow on drugs (McIntyre 2019; LaMattina 2015).

Although our paper was motivated by rising drug spending and the potential role of all sectors in the pharmaceutical supply chain, high returns in the insurance sector may also reflect profits generated from non-pharmaceutical medical care. For example, the recent decline in use of medical care during the Covid-19 pandemic-predominantly driven by postponement of elective procedures and foregone office visits-has resulted in a surge of profitability for health insurance companies (Abelson 2020). Since 2011, health insurers' profits and overhead have been capped by the Affordable Care Act, with insurers being required give consumers rebates using profits in excess of the cap. The degree to which this has benefited consumers is small: although annual premiums rose from $\$ 4400$ to $\$ 5000$ between 2015 and 2016 and 2017, rebates were only $\$ 6$ and $\$ 9$ in those years, respectively (Hall and McCue 2019). If insurers were passing excess returns back to patients in the form of reduced premiums, we would expect to see 
downward trends in excess returns rather than the upward trends in our study period. In addition, empirical evidence shows that market power in the insurance industry leads to lower provider prices but not lower premiums (Brief of professors as amici curiae in support of appellees and affirmance 2017). A more detailed analysis of the insurance sector and how its revenue and expense streams contribute to overall profitability is outside the scope of this paper, but an important area for future study.

Our findings also suggest that recent policy proposals which target middlemen, such as the American Patients First plan, are a step in the right direction (U.S. Department of Health and Human Services 2018). For example, policies that limit rebates by PBMs or require PBMs and insurers to pass rebates through to consumers could potentially lower PBM profits and out of pocket costs for patients using drugs, although it is possible removing rebates might shift costs to healthy patients in the form of higher premiums. Other suggested policies aimed at middlemen would increase drug price transparency, including removal of pharmacy gag clauses and requiring plan sponsors to provide patients information about drug price increases and lower cost options.

Although we find that middlemen earned consistently higher excess returns compared with the S\&P 500 during our study period, biotech companies also generated persistent excess returns. High profits could be potentially welfare improving for patients if they have improved access to high value pharmaceutical products. Indeed, the spike in biotech excess returns in 2014-2015 coincided with the approval of several Hepatitis $\mathrm{C}$ therapies, which represented a major advance in treatment. While drug development is generally riskier for biotech companies (DiMasi and Grabowski 2007), excess returns account for this risk, and therefore biotech companies are still seeing consistently high returns on their investment. This suggests that policies aimed at increasing competition in the biotech sector could be another fruitful avenue for curtailing drug spending. Despite accounting for less than $2 \%$ of total prescriptions, the proportion of total drug spending on specialty drugs has increased from $25 \%$ in 2008 to 47\% in 2017 (Iqvia Institute 2018). Although Congress passed the Biologics Price Competition and Innovation Act in 2010 to increase competition in the biologics market through the development and sale of biosimilars, only three biosimilars (out of 11 approved) are currently marketed in the US (U.S. Food and Drug Administration 2018a). Recognizing the continued lack of competition in the biologics market, the Food and Drug Administration (FDA) released the Biosimilars Action Plan in July 2018, which outlined key strategies for increasing biosimilar innovation and adoption as well as supporting market competition by reducing gaming of FDA requirements, which results in delayed approvals for biosimilars (U.S. Food and Drug Administration 2018b). To the extent that these policies promote competition, they would curtail excess returns currently enjoyed by the biotech sector.

Although branded manufacturers have higher excess returns compared with the full manufacturer industry, the potential role of generic manufacturers in rising drug prices has not been overlooked by policymakers. The practice of purchasing off-patent drugs and subsequently increasing the price received considerable media attention in recent years (Rockoff and Silverman 2015; Willingham 2016). While Maryland passed legislation to prevent price gouging, it was ruled unconstitutional (Barker 2019). Although lawmakers may attempt to prevent future instances of price gouging through legislation, this behavior in the generics market highlights a potential area for a stronger "middlemen" presence in the supply chain. 


\section{Conclusions}

Our study shows that companies in the pharmaceutical supply chain, including manufacturers and middlemen, have higher excess returns than the S\&P 500 if R\&D is treated as an expense. If we adjust excess returns and treat $R \& D$ as investment capital, pharmaceutical manufacturers' excess returns are on par with the S\&P 500, while middlemen and biotech firms earn consistently higher excess returns. Our findings suggest public policies that promote competition in all areas of the pharmaceutical supply chain are important avenues for curtailing drug spending.

Acknowledgements None.

Funding None.

\section{Compliance with ethical standards}

Conflict of interest Authors are affiliated with the Leonard D. Schaeffer Center for Health Policy \& Economics at the University of Southern California. The Leonard D. Schaeffer Center for Health Policy \& Economics is supported by gifts and grants from individuals, corporations, and associations; by government grants and contracts; and by private foundations. Specific information about our funding sources is available on the Schaeffer website; a complete list of donors may be found in the annual report. This study was conceived by the authors and was not supported by any particular donor, and the authors are solely responsible for the design of this study and its findings. No funder contributed to any of the following: design and conduct of the study; collection, management, analysis, and interpretation of the data; preparation, review, or approval of the manuscript; and decision to submit the manuscript for publication. Dr. Sood reports personal fees from American Medical Association, personal fees from Virta Health, personal fees from China Development Research Foundation and PhRMA, personal fees from MDL law firms, personal fees from Precision Health Economics, and personal fees from $\mathrm{H} \& \mathrm{H}$ Wholesale, outside the submitted work. Dr. Mulligan reports personal fees from Precision Health Economics. KZ has no disclosures.

\section{References}

Abelson, R. (2020). Major U.S. health insurers report big profits, benefiting from the pandemic. New York Times. Retrieved August 5, 2020, from https://www.nytimes.com/2020/08/05/health/covid-insuranceprofits.html.

Barker, J. (2019). U.S. Supreme Court denies Maryland bid to revive law aimed at preventing "monstrous" generic drug price increases. The Baltimore Sun. Retrieved February 19, 2019, from https://www.balti moresun.com/politics/bs-md-drug-price-gouging-decision-20190219-story.html.

Berk, J. B., \& DeMarzo, P. M. (2017). Corporate finance (4th ed.). Boston: Pearson.

Berndt, E. R., Nass, D., Kleinrock, M., \& Aitken, M. (2015). Decline in economic returns from new drugs raises questions about sustaining innovations. Health Affairs, 34(2), 245-252.

Bernstein, L. (2018). Largest U.S. drug distributor accused of illegally handling cancer medication. The Washington Post. Retrieved April 6, 2018, from https://www.washingtonpost.com/national/health-scien ce/largest-us-drug-distributor-accused-of-illegally-handling-cancer-medication/2018/04/06/11ff4 2a8-39c2-11e8-acd5-35eac230e514_story.html?utm_term=.916f8e97c1a8.

Brief of professors as amici curiae in support of appellees and affirmance. (2017). US vs. Anthem Inc and Cigna Corporation, No. 17-5024. Retrieved September 2020, from https://www.hbs.edu/faculty/Profi le\%20Files/Amicus\%20Brief\%20in\%20re\%20Anthem-Cigna\%20Proposed\%20Merger\%202017_7df89 27a-b54b-4ea2-a49c-55c98d6ef15c.pdf.

Britt, R. (2007). Growing share of "Big Three" gets federal attention. MarketWatch. Retrieved May 30, 2007, from https://www.marketwatch.com/story/growing-share-of-big-three-drug-wholesalers-getsattention.

Cohen, R., \& Villarroel, M. (2013). Strategies used by adults to reduce their prescription drug costs: United States. National Center for Health Statistics; 2015 January (NCHS Data Brief). Report No.: 184. 
Damodaran, A. (1999). Research and development expenses: Implications for profitability measurement and valuation. NYU Working Paper No FIN-99-024.

Damodaran, A. (2012). Investment valuation: Tools and techniques for determining the value of any asset, Wiley finance series (3rd ed.). Hoboken, NJ: Wiley.

Danzon, P. M., \& Furukawa, M. F. (2008). International prices and availability of pharmaceuticals in 2005. Health Affairs, 27(1), 221-233.

Deloitte. (2019). Ten years on: Measuring the return from pharmaceutical innovation 2019. Deloitte Center for Healthcare Solutions.

DiMasi, J. A. (2002). The value of improving the productivity of the drug development process: Faster times and better decisions. PharmacoEconomics, 20(Supplement 3), 1-10.

DiMasi, J. A., \& Grabowski, H. G. (2007). The cost of biopharmaceutical R\&D: Is biotech different? Managerial and Decision Economics, 28(4-5), 469-479.

DiMasi, J. A., \& Grabowski, H. G. (2012). R\&D costs and returns to new drug development: A review of the evidence. Oxford University Press [cited 2019 February 28]. Retrieved from http://oxfordhand books.com/view/10.1093/oxfordhb/9780199742998.001.0001/oxfordhb-9780199742998-e-2.

DiMasi, J. A., Hansen, R. W., Grabowski, H. G., \& Lasagna, L. (1991). Cost of innovation in the pharmaceutical industry. Journal of Health Economics, 10(2), 107-142.

Drash, W. (2018). Medicare drug prices soar at 10 times rate of inflation, report says. CNN. Retrieved March 26, 2018, from https://www.cnn.com/2018/03/26/health/report-medicare-drug-prices-soari ng/index.html.

Drug Quality and Security Act. Sect. 127 Stat. 587, 113-54 November 27, 2013.

Federal Trade Commission. (2015). Cardinal health agrees to pay $\$ 26.8$ million to settle charges it monopolized 25 markets for the sale of radiopharmaceuticals to hospitals and clinics. Retrieved April 20, 2015, from https://www.ftc.gov/news-events/press-releases/2015/04/cardinal-health-agree s-pay-268-million-settle-charges-it.

Fein, A. (2018). The 2018 economic report on U.S. pharmacies and pharmacy benefit managers. Drug Channels Institute. February.

FTC v. Cardinal Health, Inc., and Bergen Brunswig Corp. (1998). Retrieved August 2018, from https ://www.ftc.gov/enforcement/cases-proceedings/9810025/mckesson-corp-amerisource-health-corp.

Grabowski, H., Vernon, J., \& DiMasi, J. A. (2002). Returns on research and development for 1990s new drug introductions. PharmacoEconomics, 20(Supplement 3), 11-29.

Grabowski, H. G., \& Vernon, J. M. (1994). Returns to R\&D on new drug introductions in the 1980 s. Journal of Health Economics, 13(4), 383-406.

Guidelines for State Licensing of Wholesale Prescription Drug Distributors. 55 FR 38023 September 14, 1990.

Hall, M., \& McCue, M. (2019). How the ACA's medical loss ratio rule protects consumers and insurers against ongoing uncertainty. The Commonwealth Fund. Retrieved September 2020, from https:// www.commonwealthfund.org/publications/issue-briefs/2019/jul/how-aca-medical-loss-ratio-ruleprotects-consumers-insurers.

Hancock, J., \& Tribble, S. J. (2018). Pharmaceutical industry's promises to cut drug prices have been heard before. USA Today. Retrieved July 25, 2018, from https://www.usatoday.com/story/news/ nation/2018/07/25/prescription-drugs-industry-has-long-promised-cut-prices/830704002/.

Haninger, K. (2018). New analysis shows that more medicines worldwide are available to U.S. patients. The Catalyst. Retrieved August 2018, from https://catalyst.phrma.org/new-analysis-shows-thatmore-medicines-worldwide-are-available-to-u.s.-patients.

Hansen, R. (1979). The pharmaceutical development process: Estimate of developmental costs and times and the effects of proposed regulatory changes. In R. A. Chien (Ed.), Issues in pharmaceutical economics. Lexington, MA: D.C. Heath and Co.

Hay, M., Thomas, D. W., Craighead, J. L., Economides, C., \& Rosenthal, J. (2014). Clinical development success rates for investigational drugs. Nature Biotechnology, 32(1), 40-51.

Iqvia Institute. (2018). Medicine use and spending in the U.S.: A review of 2017 and outlook to 2022. April.

Kliff, S. (2018). The true story of America's sky-high prescription drug prices. Vox. Retrieved March 10, 2018, from https://www.vox.com/science-and-health/2016/11/30/12945756/prescription-drug-price s-explained.

Lakdawalla, D., \& Sood, N. (2013). Health insurance as a two-part pricing contract. Journal of Public Economics, 102, 1-12.

LaMattina, J. (2015). Impact of "Me-Too" drugs on health care costs. Forbes. Retrieved January 19, 2015, from https://www.forbes.com/sites/johnlamattina/2015/01/19/impact-of-me-too-drugs-onhealth-care-costs $/$ sh $=62$ de 3 bcb $1 \mathrm{c} 36$. 
Ledley, F. D., McCoy, S. S., Vaughan, G., \& Cleary, E. G. (2020). Profitability of large pharmaceutical companies compared with other large public companies. JAMA, 323(9), 834.

McIntyre, G. (2019). Enough with the me-too drugs. New treatments should be worthy of the people who invest their lives in clinical trials. STAT. Retrieved September 4, 2019, from https://www.statnews. com/2019/09/04/me-too-drugs-cancer-clinical-trials/.

Palepu, K. G., \& Healy, P. M. (2013). Business analysis and valuation: Using financial statements (5th ed.). Mason, OH: South-Western, Cencage Learning.

Pharmaceutical Care Managment Association. (2018). New data: Rebates are unrelated to drugmakers' pricing strategies. Retrieved August 15, 2018, from https://www.pcmanet.org/new-data-rebates-areunrelated-to-drugmakers-pricing-strategies/.

Pierson, B. (2017). AmerisourceBergen pleads guilty over syringes, to pay $\$ 260 \mathrm{mln}$. Reuters. Retrieved September 27, 2017, from https:/www.reuters.com/article/us-amerisourcebergn-settlement/ameri sourcebergen-pleads-guilty-over-syringes-to-pay-260-mln-idUSKCN1C22JN.

Rockoff, J. D., \& Silverman, E. (2015). Pharmaceutical companies buy rivals' drugs, then jack up the prices. Wall Street Journal. Retrieved April 26, 2015, from https://www.wsj.com/articles/pharmaceuticalcompanies-buy-rivals-drugs-then-jack-up-the-prices-1430096431.

Sagonowsky, E. (2017). The top 15 generic drugmakers by 2016 revenue. FiercePharma. Retrieved May 16, 2017, from https://www.fiercepharma.com/special-report/top-15-generic-drugmakers-2016.

Sherman, D., \& Young, S. D. (2001). Tread lightly through these accounting minefields. Harvard Business Review. Retrieved July, 2001, from https://hbr.org/2001/07/tread-lightly-through-these-accounting -minefields.

Sood, N., Shih, T., Van Nuys, K., \& Goldman, D. (2017). The flow of money through the pharmaceutical distribution system. USC Schaeffer White Paper. June.

Standard \& Poor's/Compustat. (2013). Compustat North America Data. Retrieved September 2020, from Warton Research Data Services.

Thomas, D., Burns, J., Audette, J., Carroll, A., Dow-Hygelund, C., \& Hay, M. (2016). Clinical development success rates 2006-2015. San Diego: Biomedtracker.

Thomas, K., \& Ornstein, C. (2018). The price they pay. The New York Times and ProPublica. Retrieved March 5, 2018, from https://features.propublica.org/drug-prices/high-cost-drugs-the-price-they-pay/.

Tracer, Z., \& Langreth, R. (2018). Mergers that built drug middlemen need review, GOP lawmakers say. Bloomberg. Retrieved July 27, 2018, from https://www.bloomberg.com/news/articles/2018-07-27/ mergers-that-built-drug-middlemen-need-review-gop-lawmakers-say.

United States Government Accountability Office. (2017). Drug industry: Profits, research and development spending, and merger and acquisition deals. GAO-18-40. 2017 November.

US Congress, Office of Technology Assessment. (1993). Pharmaceutical R\&D: Costs, risks, and rewards. OTA-H-522. 1993 February.

U.S. Department of Health and Human Services. (2018). American Patients first: The Trump administration blueprint to lower drug prices and reduce out-of-pocket costs.

U.S. Food and Drug Administration. (2018a). Remarks from the FDA Commissioner Scott Gottlieb, M.D., as prepared for the delivery at the Brookings Institution on the release of the FDA's Biosimilars Action Plan. Retrieved July 18, 2018, from https://www.fda.gov/NewsEvents/Newsroom/PressAnnounceme nts/ucm613881.htm.

U.S. Food and Drug Administration. (2018b). Biosimilar action plan: Balancing innovation and competition. July.

Willingham, E. (2016). Why did Mylan Hike EpiPen prices 400\%? Because they could. Forbes. Retrieved August 21, 2016, from https://www.forbes.com/sites/emilywillingham/2016/08/21/why-did-mylan -hike-epipen-prices-400-because-they-could/\#593d5f9d280c.

Wong, C. H., Siah, K. W., \& Lo, A. W. (2018). Estimation of clinical trial success rates and related parameters. Biostatistics. 2018 January 31 [cited 2018 August 19]. Retrieved from https://academic.oup.com/ biostatistics/advance-article/doi/10.1093/biostatistics/kxx069/4817524.

Publisher's Note Springer Nature remains neutral with regard to jurisdictional claims in published maps and institutional affiliations. 